\title{
Design of the Smart Vessel Platform using the Remote Monitoring Technique
}

\author{
Jongan Park, SungkwanKang, TaejinHa, Jimin Lee and Sangeon Oh \\ Chosun University, Intersave Co., Ltd. and Donghatech Co., LTD. \\ japark@chosun.ac.kr
}

\begin{abstract}
The intention of a vessel platform is to control or monitor systems or sensors in the vessel control panel as well as provide diverse marine information.

In this study a smart vessel platform design is shown which can be used to monitor the data of control systems and sensors in the vessel as well as provide dive se marine information. With it, the base which provides information on the vessel and service information is available. Also, it is expected that through use of this system narine accidents which might occur during navigation can be prevented, marine information can be provided and the safety and efficiency of the system can be enhanced.
\end{abstract}

Keywords: marine information, vessel platform, remote monitoring, navigation, marine accident

\section{Introduction}

Recently, as control systems and sensors in vessels have increased, there has been research on development of a platform to control or monitor them. In particular, with the development of IT technology and mobile communications, diverse attempts to provide various services Involving the platform have been made. If previous vessel platforms controlled or monitored control systems and sensors in the control panel of the vessel, a smart vessel patform can create remote monitoring using mobile communication technology from close by or from a long distance. By monitoring specific behavior of a vesse (11) real-time, different types of incidents which might occur during navigation can be prevented, marine information can be provided and the safety and efficiency of thesystem during navigation can be enhanced.

Therefore, for safe and economical navigation of a vessel, it is necessary to efficiently manage the data that come from each system in a vessel [1]. In the U.S.A. and the E.U. there have been humber of studies on digital vessels including research and development on digital vessel integration and land support systems for vessel navigation. [2].

\section{Development Trends of the Vessel Monitoring System and Navigation Platform}

\subsection{AIS (Automatic Identification System)}

Marine accidents by a vessel are accompanied by damages due to environmental pollution in the ocean as well as economic loss of the vessel and the cargo itself, and in particular, an oil spills by oilers brings enormous losses to coastal sea areas as well as harbours. Therefore, advanced maritime powers have tried to secure safe navigation by 
controlling navigation in the ocean as well as on coastal routes. For this purpose, an automatic identification system (AIS) which was originally developed for aircraft has been expanded to seagoing vessels, and an Automatic Identification System(AIS) for vessels was developed and applied for seagoing vessel. As the International Maritime Organization(IMO) enacted AIS performance standards in July, 1997 and inserted AIS carriage requirements into Section 1.5, Rule 19, Chapter 5 of the Revised SOLAS, the systems has been loaded on vessels since July 1, 2002 stepwise.

This AIS is an advanced system which is designed to prevent collisions of vessels on the ocean and provide navigation information such as positions, courses, and velocity in real-time. If AIS is introduced, it is possible to judge the existence and progress of other vessels in cases when the surrounding vessels cannot be recognized and safety controls such as prevention of vessel collision, wide control, and search and rescue for shipwrecked vessels can be effectively performed in cases when visibility is rot good.

The AIS can be connected with a personal computer (an electronic nayigation chart) even though it does not have a keyboard and send simple sentence communication to prevent collisions. Also, it provides information such as a ships route, velocity, and position to other vessels to prevent the collision of vessels in the ocean, retrieve basic navigation information from other vessels in real-time and based on the information, it helps the vessel be controlled by a Vessel Traffic Service(VTS).

The IMO requires international passenger ships and navigation ships over 300 -tons to install an AIS terminal and for base stations o be built octhe coastlines. Base stations have been built in our coastal areas.

AIS's information transmission period is designatedaccording to the moving speed of a vessel: the period for a ships at anchor is threaminutes, that of 0-14 knot ship is 12 seconds, and that for a vessel traveng more than 23 knots is every third minute.

\section{Table . Information of AIS Data}

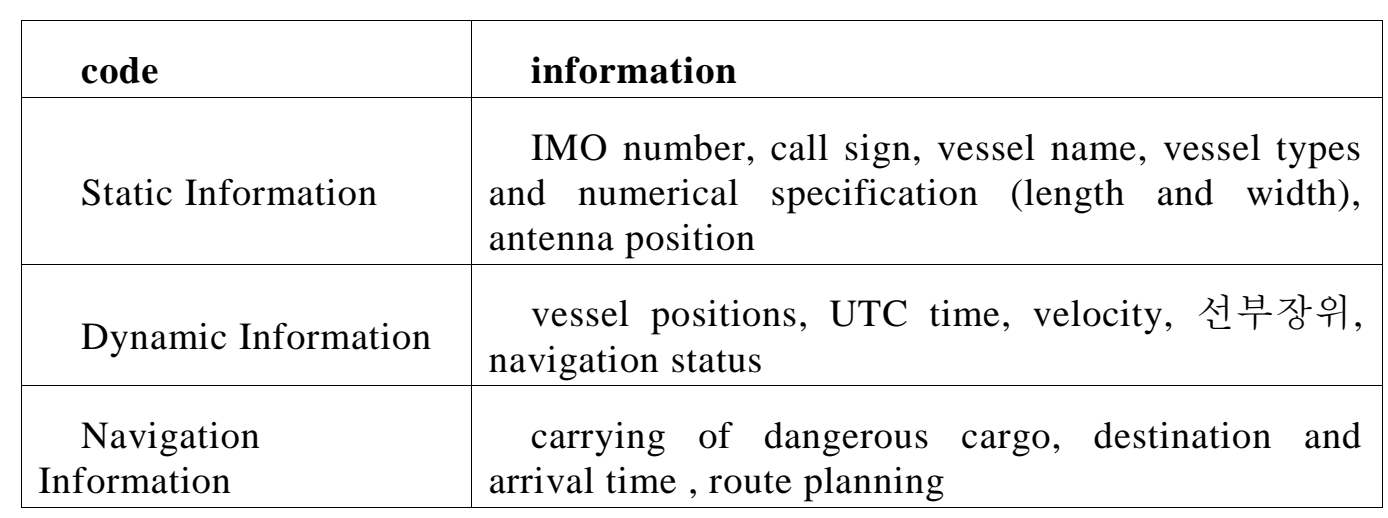

\subsection{Related Research}

Lee [3] proposed a vessel status monitoring system which can monitor the status of the vessel and the surrounding environment. For the proposed vessel monitoring, reliability and communication speed were enhanced through CAN communication which can control in real-time. For safety and efficiency in electronic sailing technology, RFID communication was used. For the boiler room in a vessel, a CAN cable network was integrated with a mobile network and to check the status of the containers outside the vessel. 
Lee [4] analysed information of the AIS system which automatically sends information on a vessel that is broadcast to the vessel and the land and receives information on neighboring vessels. Based on the information received, it classified the information on the neighboring vessels and displayed it in Google Map using HTML5. Kim [5] realized a system where a network of systems and equipment in developed that transmits information to the shore through an integrated protocol for management and support from land.

Lee [6] developed a vessel motion control system based on Oldenburger's control theory which mathematically imitates the motion characteristics of a vessel and designed an autonomous vessel navigation and motion control system.

For the system proposed by Weilian [7], building and maintenance expenses are low because installment and maintenance is easy. As USN, which is built in a mobile environment, uses mobile communication and a network with low specifications, fow speed, and with low expense, a zigby communication system can be built and used. Endsley [8] designed a risk analysis system based on USN middleware and vessel context-awareness as a vessel is affected by resistance and sway motion as the vessel contacts sea water directly during navigation by waves and current.

To more effectively integrate diverse artificial intelligence systems in the intelligent autonomous navigation system, a model of a Reactive Layer Virtual World ConsiderativeLayer(RVC) was proposed, The RVC model which has a sharing information storage area called a virtual environment collects diverse spieces of information on a vessel and realizes damage detection, navigation, collision avoidance, and vessel motion control using artificial intelligence[9].

Lee [10] developed a composite navigation suppon platform. It provides remote support service and a remote support platform through an intelligent maintenance and management system, a vessel context monitoring service, and an optimal navigation performance support system according to navigation records and real-time vessel context, and supports a vessel environment support platform through an accident history management system and risk monitoring system.

\section{Design of the Smart Vessel Platform in this Study}

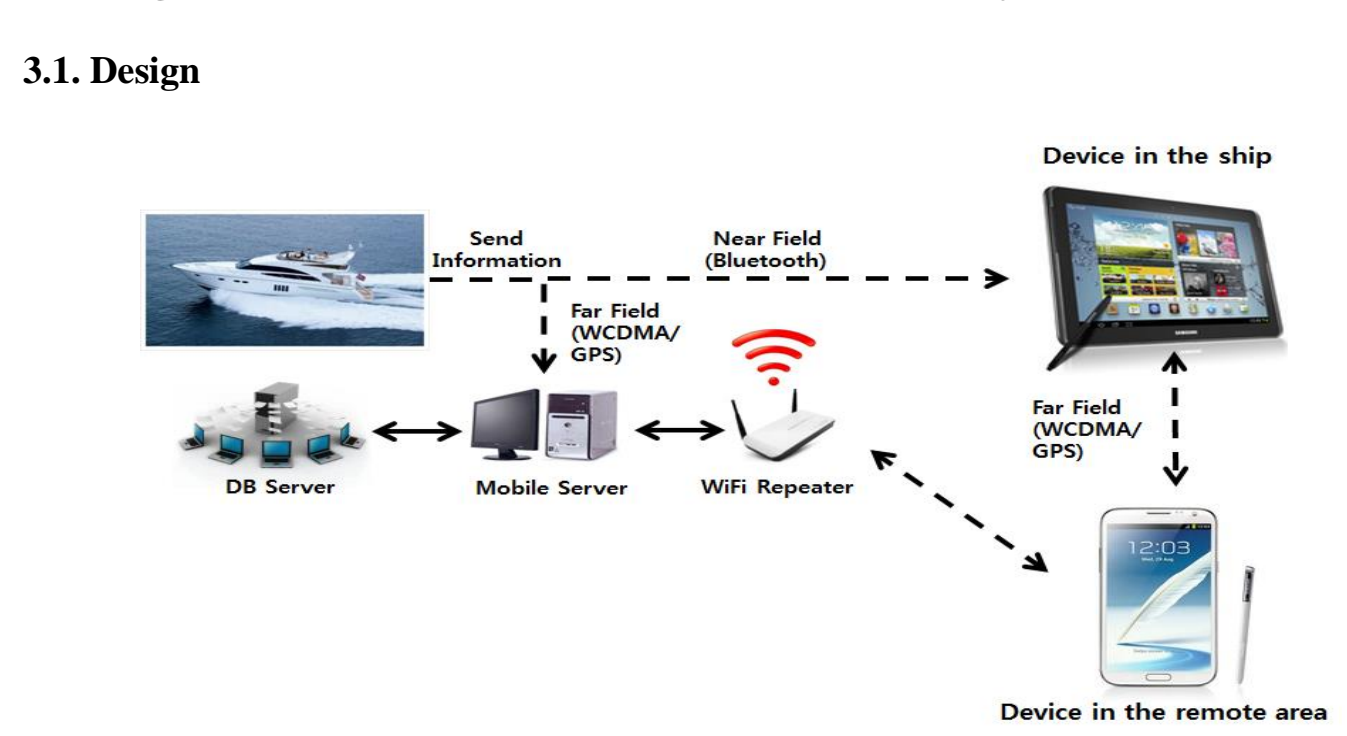

Figure 1. Concept of the Smart Vessel Platform 
Figure 1 shows the smart vessel platform realized in this study. The platform uses NFC communication and smart systems in a vessel during navigation to identify information on the vessel. Also, WCDMA or GPS systems send vessel information to the server remotely and support its identification using smart devices. Finally, through WCDMA, it supports identification of the information on the vessel by connecting smart devices in the vessel to those in a remote area.

\subsection{Implementation}

Figure 2 shows the configuration of sectors in the initial menu screen of the smart vessel platform designed. The menu was composed of remote monitoring to output remote data, navigation to provide information on positions, marine information, leisure information and an environmental setting menu.

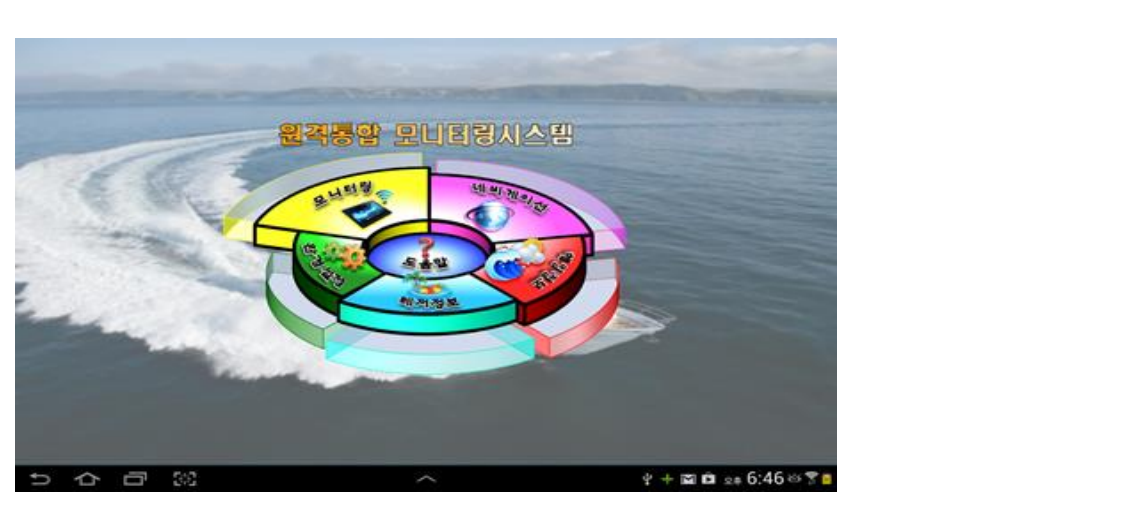

Figure 2. Interface of a Menu Screen

Figure 3 is a service screen toprovide weather and leisure information and maps to a vessel in navigation, for Which weather and leisure information was obtained from relevant sites(The Korean Meteorological Association and The Korean Ocean Research Institute). Naver Map was used and locations in the ocean were overlaid on the map with real latitude and longitude locations.

Click on the overlaid icons and the weather of the location is displayed to the right of the screen.

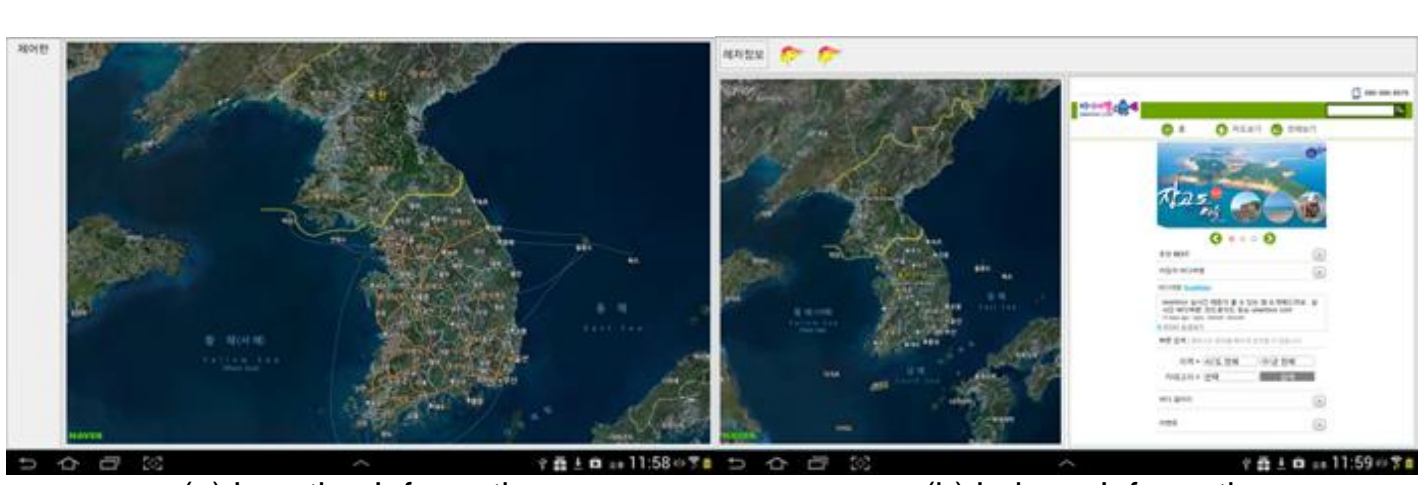

(a) Location Information

(b) Leisure Information 


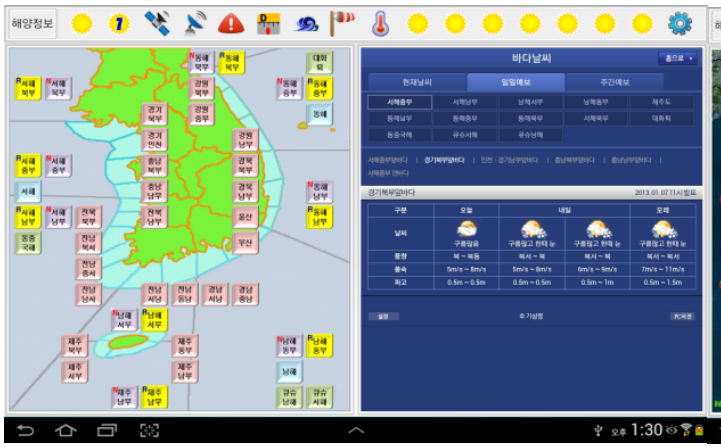

(c) Sectional Weather Information

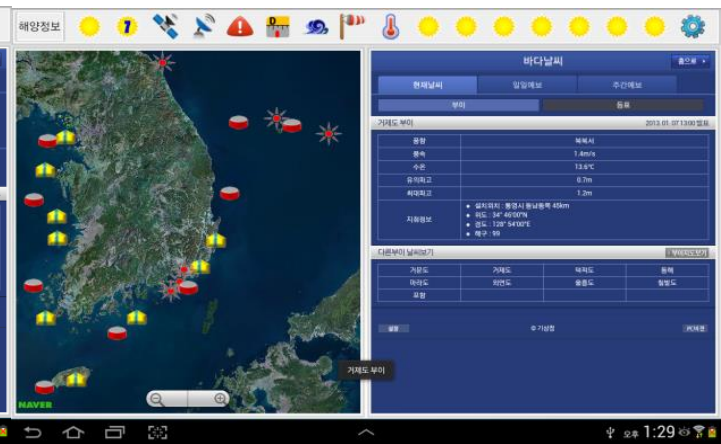

(d) Ocean Point Weather Information

Figure 3. Information Supply Service Screen

Figure 4 presents a module which transmits data with smart systems in remote areas by realizing a virtual system which transmits vessel information: (a) sends information on current virtual navigation, problems, and position and (b) analysis data is sent and displayed on screen.

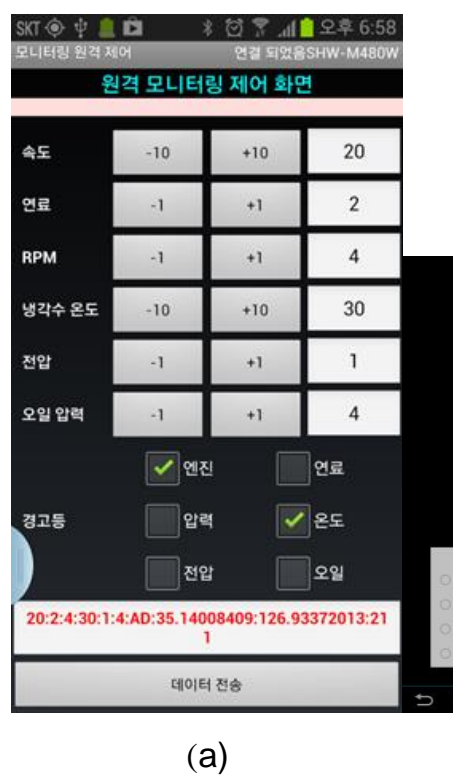

(a)

(a) Remote monitoring transmission screen

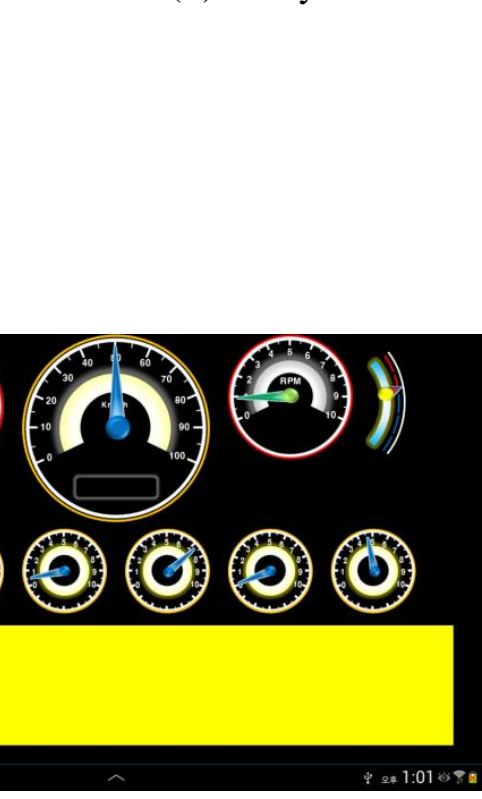

(b)

Figure 4. Remote Monitoring Screen

Figure 5 is the vessel monitoring system designed in this study. The system is composed of an information transmission and receiving system and an information display system which is installed in smart systems with remote areas.

The vessel monitoring system automatically transmits the latitude, longitude, and velocity of each vessel using values from the GPS system and the sensor in a smart phone when the movement direction of the vessel is matched with a smart system and the system is activated. The information transmitted is displayed in a vessel where information display systems are installed or in the smart system of remote areas. 


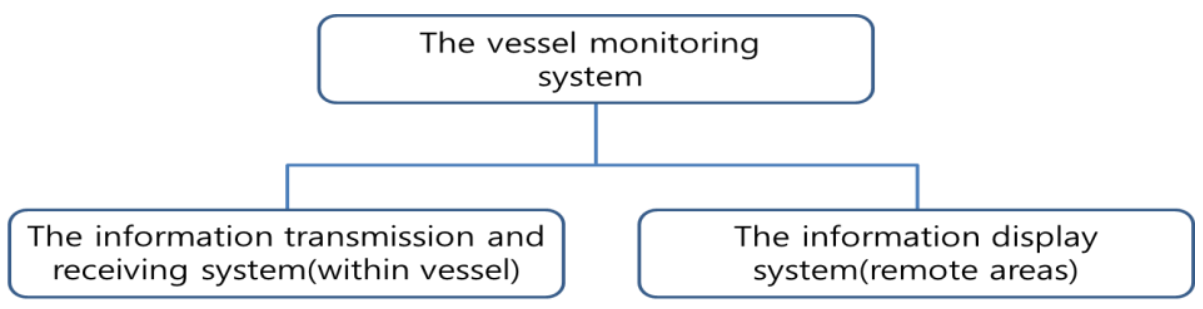

Figure 5.Composition of Vessel Monitoring System

Figure 6 shows the screen of the vessel monitoring system designed in this study. If the vessel displayed on the map is clicked, its information can be displayed in real-time. If the menu around the icons is selected, specific information of the vessel and message communication are available.

Also, option menus or help is available if an icon is clicked.

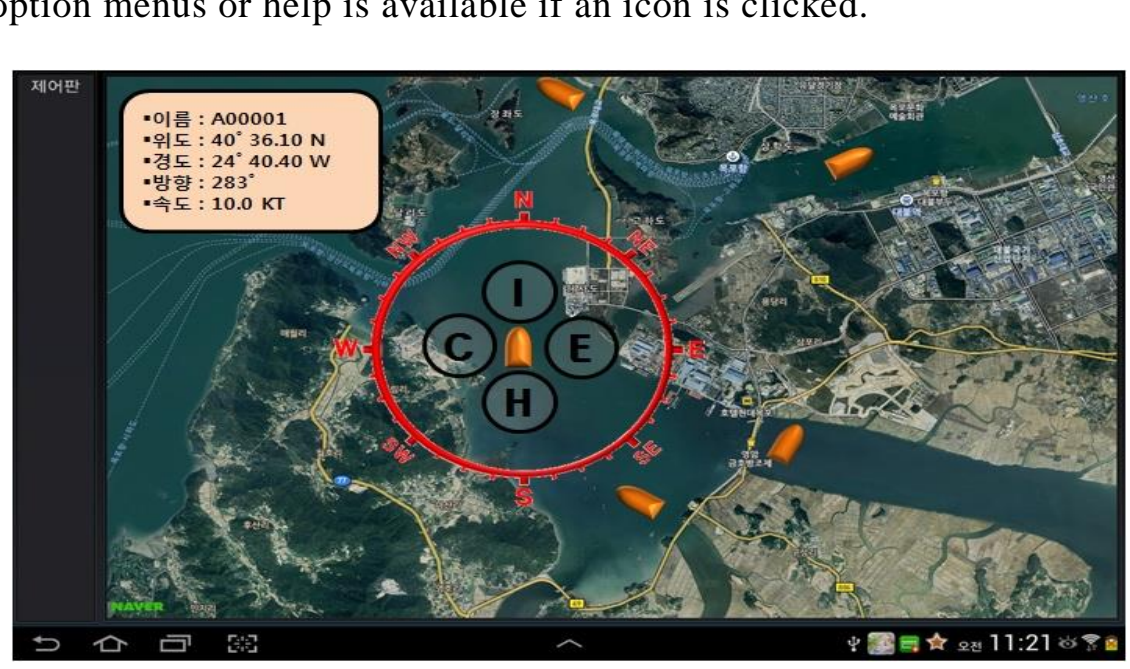

Figure 6. Design Screen of Vessel Monitoring System

Figure 7 shows communication between vessels displayed when a communication icon is clicked. If a desired vessel is clicked from the vessel list, message communication with it is ayailable.

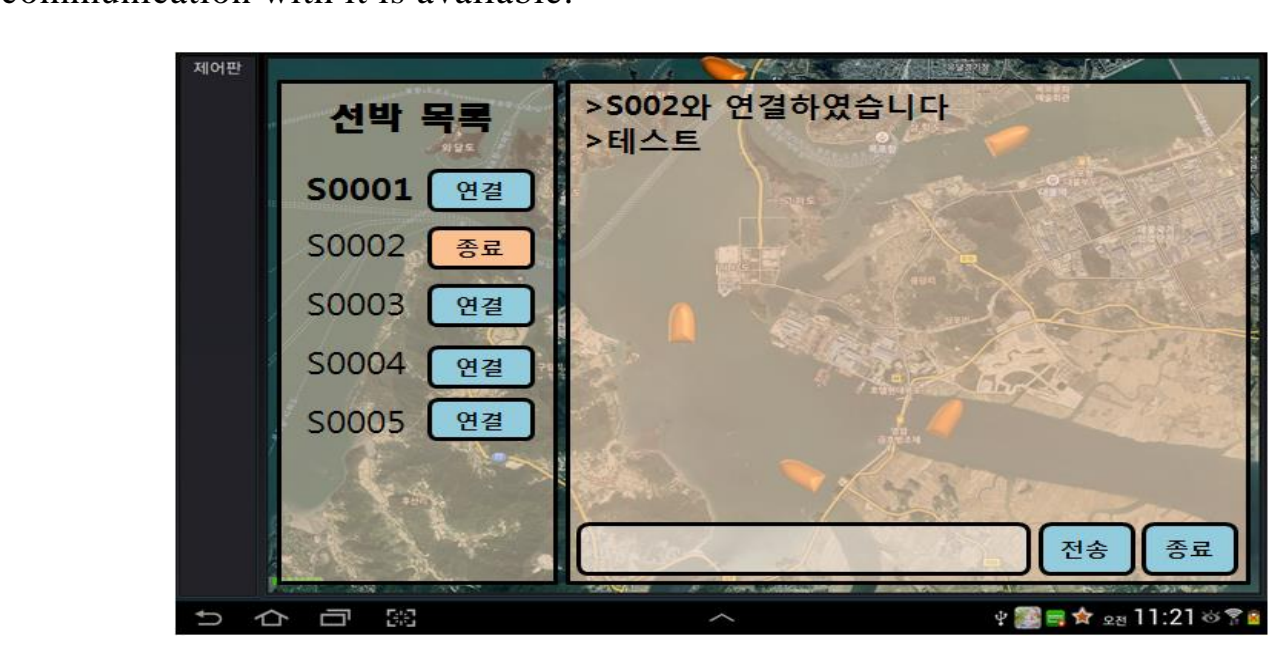

Figure 7. Communication between Vessels 
Figure 8 shows a screen displaying a warning message from the system designed in this study or emergency message from other vessels or control systems.

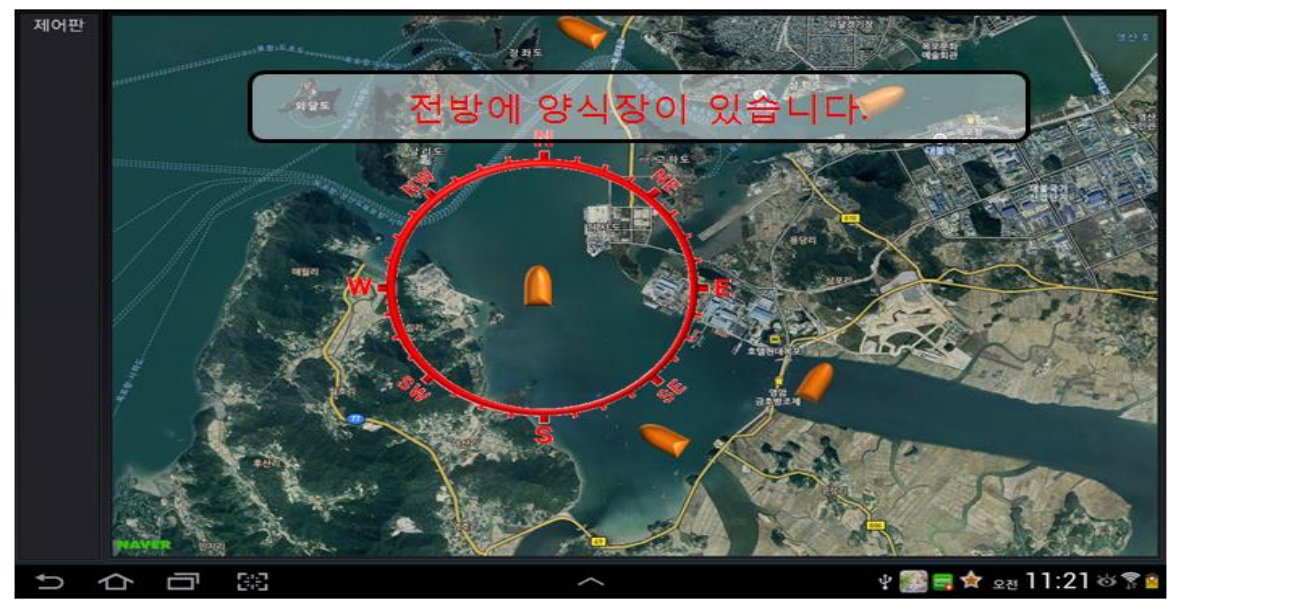

Figure 8. Warning

\section{Conclusion}

This study designed a smart vessel platform which can provide diverse marine information as well as monitor data of control systems and sensors in remote areas. The platform realized can check information on vessel through smart systems using NFC communication anywhere in a vessel

Also, the smart system can check the information on a vessel which is transmitted to a server in a remote area by connecting WCDMA and WIPI to the GPS system. With the use of WCDMA communication, the smart system in a vessel which is connected with that in the remote arean check the information on the vessel.

Finally, it is expected that such a smart vessel platform can prevent maritime accidents, provide marme information and enhance stability and efficiency of the system during nafigation as well as provide information on a vessel from a remote area and a variety of service information.

Further research should grve focus to development of a system which is connected to WCDMA communication for long-distance tests and its connection test with real vessels for verification in an ocean environment.

\section{Acknowledgements}

This work was financially supported by Leadingindustry in Honam Economic BeltDevelopment Project.

\section{References}

[1] ISM Code \& Guide Lines On Implementation, IMO, (1997).

[2] E. S. Petersen, "The Intelligent Ship", Waterborne Transport's Role in Future Intelligent Transport Systems - Lessons learned in EC RTD that contribute to and ITS vision, Wilhelmshaven, June, ${ }^{\text {th }}, \mathbf{( 2 0 0 0 )}$.

[3] S. J. Lee, C. H. K, G. S. Ro, S. Y. Choi, S. I. Kang and Y. Y. Choo, "Desing and Implementation of Shipboard Monitoring System”, 2008 KMMS Fall Conference Proceeding, (2008), pp. 59-63.

[4] S. J. Lee and J. W. Lee, "A Development of AIS Vessel Monitoring System on online map using HTML5", Journal of Navigation and Port Research, vol. 35, no. 6, (2011), pp. 463-467. 
[5] J. Y. Kim, S. T. Chung, J. S. Ieem, J. W. Park and Y. K. Lim, "Design of Shipboard integrated network platform for Digital-ship”, The journal of KIMICS, vol. 9, no. 6, (2005), pp. 1202-1210.

[6] W. H. Lee, C. M. Kim, J. L. Choi and Y. G. Kim, "A Ship Motion Control System for Autonomous Navigation", The journal KIISE, vol. 9, no. 6, (2003), pp. 674-682.

[7] W. Su, O. B. Akan and E. Cayirci, "Communication Protocol for Sensor Networks", Wireless Sensor Network, Kluwer Acasdemic Publisher, (2004), pp. 21-509.

[8] M. R. Endsley, "Theoretical underpinnings of situation awareness", Lawrence Erlbaum Associates, Publishers, Mahwah, New Jersey, (2000), pp. 3-32.

[9] C. M. Kim and Y. G. Kim, "The Study on Intelligent Control Architecture of Unmanned Autonomous Vehicle", KIIS 2000 Fall Conference Proceeding, vol. 10, no. 2, (2000), pp. 172-175.

[10] J. W. Lee, H. S. Jung and Y. K. Lim, "Development of the Total Navigation Support Platform of the DigitalShip", The journal of SNAK, vol. 49, no. 2, (2012), pp. 7-14.

\section{Authors}

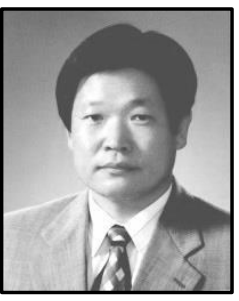

\section{Jong-anPark}

1983-1984: visiting professor in department of electr c \& electronic Engineering, Massachusetts state university of the US

1990-1991: visiting professor in Departmegnt of electric \& electronic engineering, Surrey state univensity of the UK

1975-currently: professor in Depastment of information communication engineering, Chosun University.

Research interests: Digital signal $\diamond$ pocessing, multimedia image processing, RFID

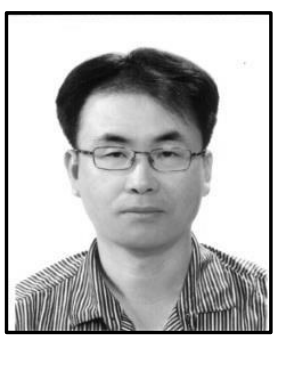

\section{Sung-kwan Kang}

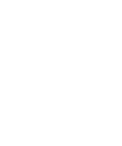

1997. B. S. degrees in Electronic Engineering, Chosun University 1999. MS. degrees in Electronic Engineering, Chosun University 2005.P. D. degrees in Electronic Engineering, Chosun University Present. CTO An Intersave Co., Ltd.

Research interests : game production technique, NFC technique and multimedia processing

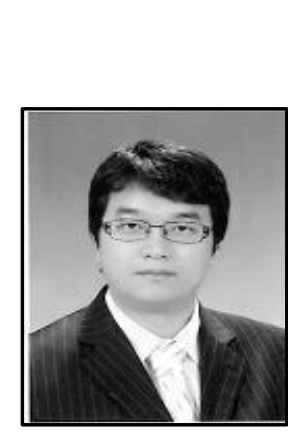

\section{Tae-jinHa}

2005. M. S. degrees in Information and Communication engineering, Chosun University.

2012. Ph.D. degrees in Information and Communication Engineering, Chosun University.

Present. Development Manager in Dong-ha Tech.

Research interests: IT convergence, information security. 


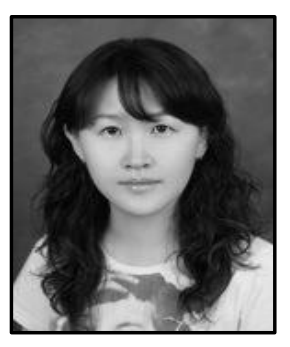

\section{Ji-min Lee}

2002. B.S degrees in Information engineering, Chonnam University. 2011. M.S. degrees in Information Communication and Engineering, Chosun University.

Present. Candidate for the Ph.D. in Information Communication and Engineering, Chosun University.

Research interests: multimedia image processing, pattern recognition, image searching

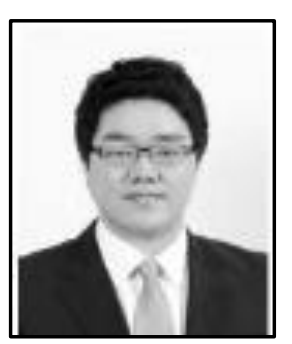

\section{Sang-eon Oh}

2011. B. S. degrees in Electronic Computer Engineering, Chonnam University

Present. Candidate for the M.S. degrees in Information Communication and Engineering, Chosun University

Research interests: image segmentation, medical image processing, signal processing

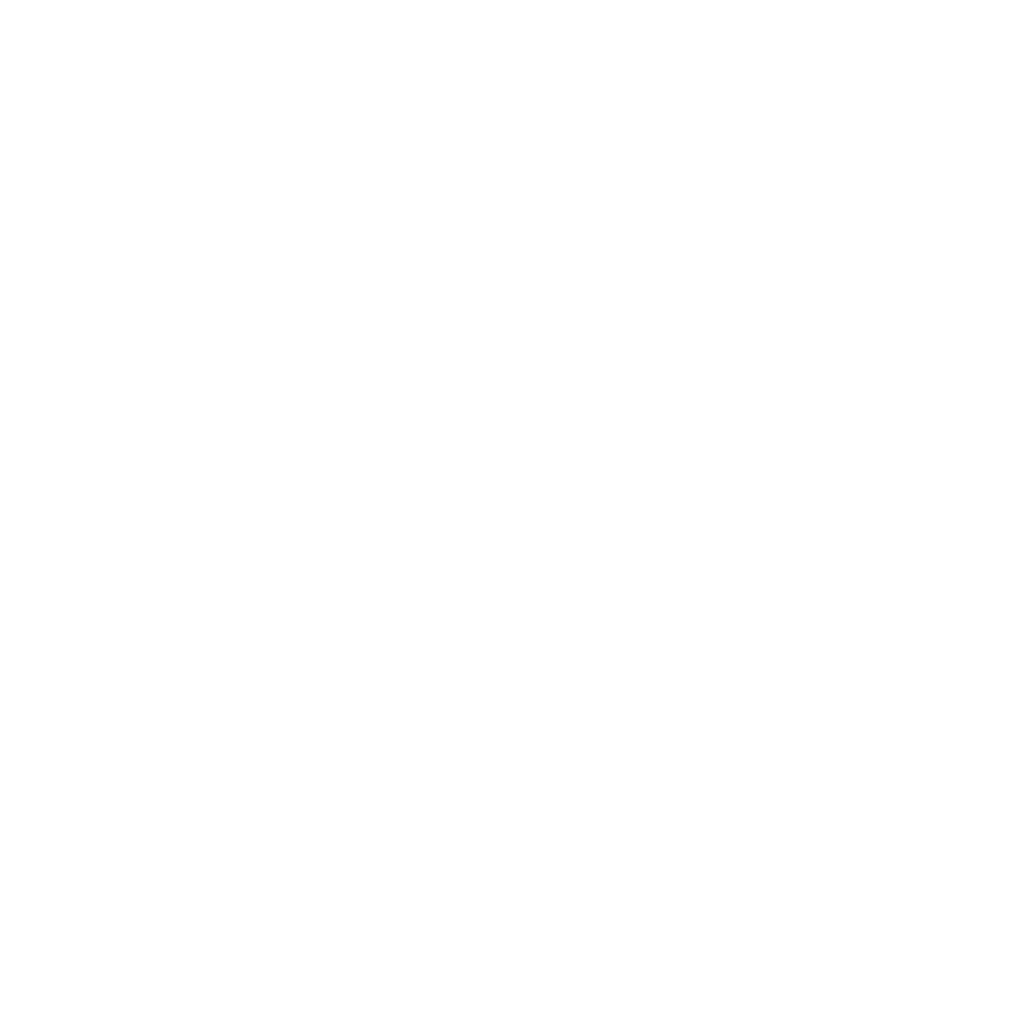


International Journal of Smart Home

Vol.8, No.1 (2014)

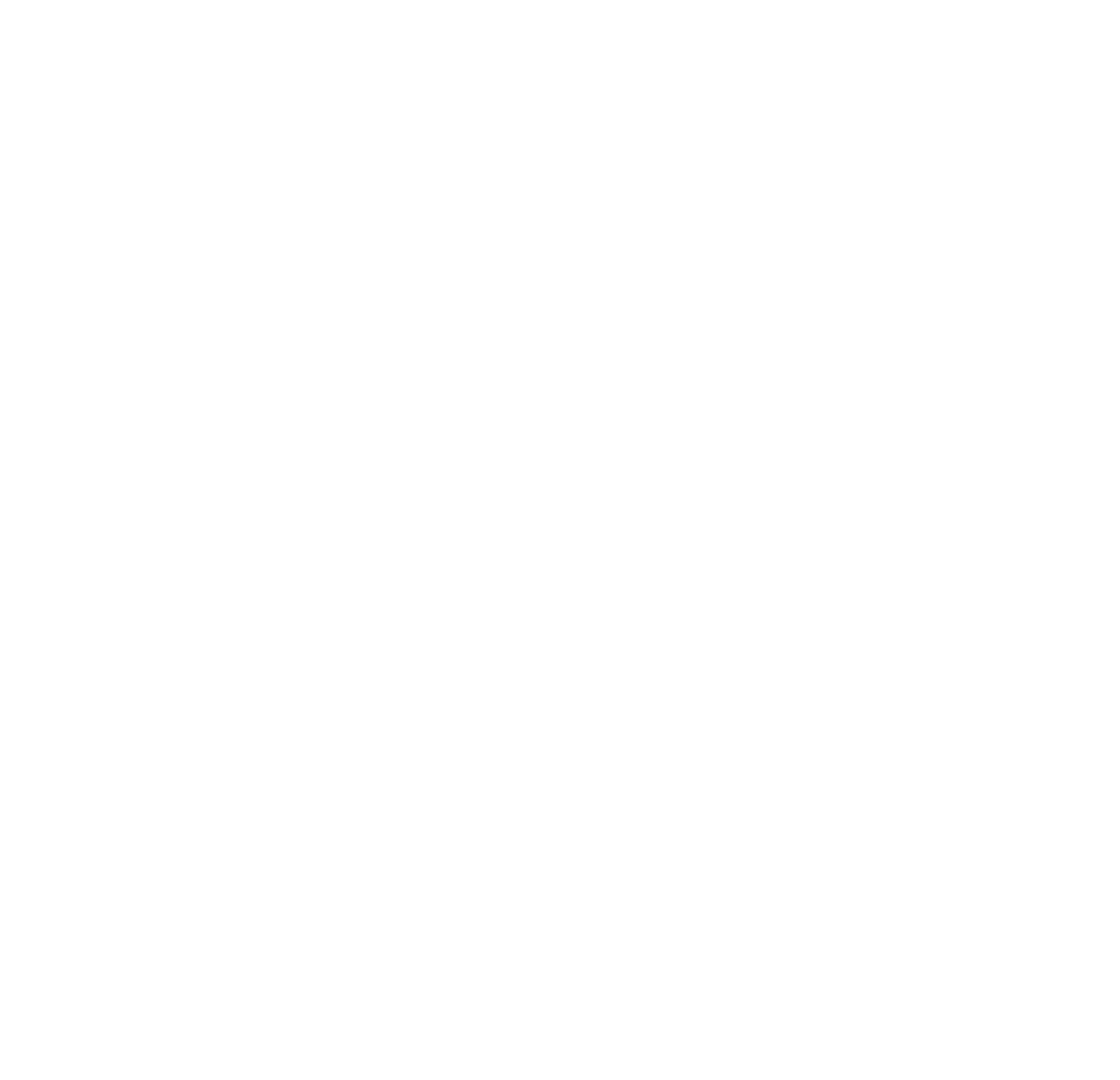

